\title{
Improved representation of East Antarctic surface mass balance in a regional atmospheric climate model
}

\author{
J.M. VAN WESSEM, ${ }^{1}$ C.H. REIJMER, ${ }^{1}$ M. MORLIGHEM, ${ }^{2}$ J. MOUGINOT, ${ }^{2}$ E. RIGNOT, ${ }^{2}$ \\ B. MEDLEY, ${ }^{3}$ I. JOUGHIN, ${ }^{4}$ B. WOUTERS, ${ }^{5}$ M.A. DEPOORTER, ${ }^{5}$ J.L. BAMBER, ${ }^{5}$ \\ J.T.M. LENAERTS, ${ }^{1}$ W.J. VAN DE BERG, ${ }^{1}$ M.R. VAN DEN BROEKE, ${ }^{1}$ \\ E. VAN MEIJGAARD ${ }^{6}$
}

\author{
${ }^{1}$ Institute for Marine and Atmospheric Research Utrecht (IMAU), Utrecht University, Utrecht, The Netherlands \\ E-mail: j.m.vanwessem@uu.nl \\ ${ }^{2}$ Department of Earth System Science, University of California, Irvine, Irvine, CA, USA \\ ${ }^{3}$ NASA Goddard Space Flight Center, Greenbelt, MD, USA \\ ${ }^{4}$ Polar Science Center, Applied Physics Laboratory, University of Washington, Seattle, WA, USA \\ ${ }^{5}$ Bristol Glaciology Centre, School of Geographical Sciences, University of Bristol, Bristol, UK \\ ${ }^{6}$ Royal Netherlands Meteorological Institute, De Bilt, The Netherlands
}

\begin{abstract}
This study evaluates the impact of a recent upgrade in the physics package of the regional atmospheric climate model RACMO2 on the simulated surface mass balance (SMB) of the Antarctic ice sheet. The modelled SMB increases, in particular over the grounded ice sheet of East Antarctica $\left(+44 \mathrm{Gta}^{-1}\right)$, with a small change in West Antarctica. This mainly results from an increase in precipitation, which is explained by changes in the cloud microphysics, including a new parameterization for ice cloud supersaturation, and changes in large-scale circulation patterns, which alter topographically forced precipitation. The spatial changes in SMB are evaluated using 3234 in situ SMB observations and ice-balance velocities, and the temporal variability using GRACE satellite retrievals. The in situ observations and balance velocities show a clear improvement of the spatial representation of the SMB in the interior of East Antarctica, which has become considerably wetter. No improvements are seen for West Antarctica and the coastal regions. A comparison of model SMB temporal variability with GRACE satellite retrievals shows no significant change in performance.
\end{abstract}

KEYWORDS: accumulation, atmosphere/ice/ocean interactions, ice and climate, ice velocity, surface mass budget

\section{INTRODUCTION}

The surface mass balance (SMB; mm w.e. $\mathrm{a}^{-1}$ ) of an ice sheet is defined as the sum of all processes that add or remove mass:

$$
\mathrm{SMB}=\int_{\text {year }}\left(\mathrm{PR}-\mathrm{SU}_{\mathrm{s}}-\mathrm{SU}_{\mathrm{ds}}-\mathrm{ER}_{\mathrm{ds}}-\mathrm{RU}\right) \mathrm{d} t
$$

where PR represents total precipitation (snowfall plus rain), $\mathrm{SU}$ is surface $\left(\mathrm{SU}_{\mathrm{s}}\right)$ plus drifting snow $\left(\mathrm{SU}_{\mathrm{ds}}\right)$ sublimation, $E R_{d s}$ is drifting-snow erosion and $R U$ is meltwater runoff, the amount of liquid water (melt and rain) that is not retained or refrozen in the snowpack. Accurate estimates of the SMB of glaciated regions are essential for assessment of their mass change and contribution to sea-level rise (e.g. Rignot and others, 2011; Shepherd and others, 2012) In remote glaciated regions such as East Antarctica, reliable SMB observations are scarce (Favier and others, 2013) and, as a result, estimates of SMB are uncertain. Remote-sensing techniques can overcome this deficiency, but pose other challenges. Mass changes from the Gravity Recovery and Climate Experiment (GRACE; Tapley and others, 2004) do not resolve small-scale features, while altimetry measurements need a correction for firn processes (Gunter and others, 2009) and inter-campaign biases (Borsa and others, 2014). Estimating ice-sheet mass balance from ice discharge using synthetic aperture radar interferometry (InSAR) ice surface velocities (Mouginot and others, 2012) requires additional information about ice thickness and groundingline position. The latter two remote-sensing techniques require SMB fields. For that reason, climate model simulations of SMB are crucial for obtaining a realistic estimate of the ice-sheet mass balance.

Regional climate models (RCMs) simulate atmospheric processes at a relatively high horizontal resolution and, when coupled to a snow model, have proven to realistically simulate the SMB and its components over glaciated regions, such as Greenland (Fettweis and others, 2011; Van Angelen and others, 2013), the Canadian Arctic Archipelago (Lenaerts and others, 2013) and Antarctica (Bromwich and others, 2004; Van de Berg and others, 2006; Lenaerts and others, 2012a). One of these RCMs is the Regional Atmospheric Climate MOdel (RACMO2). SMB fields from RACMO2 have been used to support the interpretation of GRACE (Wouters and others, 2013), InSAR (Rignot and others, 2008) and radar/laser altimetry data (Ligtenberg and others, 2012), and all these techniques have recently provided a reconciled mass-balance estimate (1992-2011) for the Greenland and Antarctic ice sheets (Shepherd and others, 2012).

Simulated SMB fields are affected by model limitations. Van de Berg and others (2005) showed that Antarctic ice sheet (AIS) SMB, simulated by a previous RACMO version, was underestimated in the ice-sheet interior, whereas it was 
overestimated along the steep coastal slopes, partly because of an insufficient horizontal resolution $(\sim 55 \mathrm{~km})$ and partly because of limitations of the physics parameterizations. Much effort has been put into improving model performance, such as using more advanced data-assimilation techniques in reanalysis products (Dee and others, 2011) that are used to force the regional models at their lateral boundaries, and increasing model resolution (Van Lipzig and others, 2004; Lenaerts and others, 2012b). In addition, there is ongoing improvement and refinement of parameterizations that represent complex subgrid physical processes in these models (Van Meijgaard and others, 2012).

Van Wessem and others (2014) presented the impact of a recent physics update of RACMO2 on the near-surface temperature and wind speed and surface energy balance (SEB) of Antarctica, finding improvements in SEB components, such as downward longwave radiation and turbulent sensible heat flux. In this study the effects of the physics update on the simulated SMB of Antarctica are evaluated, and compared with available observations. First, we present the updates of the physics package in RACMO2 that are relevant for the SMB and the observational SMB data used for model evaluation. Then we discuss the changes in the SMB and its components, and we evaluate the changes in the SMB by comparing the old and new SMB fields with observations. Finally, conclusions are presented.

\section{DATA AND METHODS \\ RACMO2 physics update}

RACMO2 combines the dynamical processes of the High Resolution Limited Area Model (HIRLAM; Undén and others, 2002) with the physics package of the European Centre for Medium-Range Weather Forecasts (ECMWF) Integrated Forecast System (IFS). The polar version of RACMO2 has been specifically adapted for use over glaciated regions, such as Greenland and Antarctica (e.g. Reijmer and others, 2005), by interactively coupling it to a multilayer snow model that calculates melt, percolation, refreezing and runoff of meltwater (Greuell and Konzelmann, 1994; Ettema and others, 2010). Surface albedo is based on a prognostic scheme for snow grain size (Kuipers Munneke and others, 2011), and a drifting-snow routine simulates the interactions of drifting snow with the surface and the lower atmosphere (Lenaerts and others, 2012c). A horizontal resolution of $27 \mathrm{~km}$ and a vertical resolution of 40 levels are used to resolve the complexity of the Antarctic climate, which is closely related to the topography of the ice sheet. The model is forced by ERA-Interim reanalysis data (January 1979-December 2011; Dee and others, 2011) at the ocean and lateral boundaries, while the domain interior is allowed to evolve freely.

Here we analyse and assess how a recent upgrade in the ECMWF-IFS physics package of RACMO2 impacts the simulated SMB and its components. The update from RACMO2.1 to RACMO2.3 included changes in the cloud scheme and cloud microphysics, as well as changes in the turbulent and radiative schemes. Van Wessem and others (2014) addressed the effects of these changes on the SEB, and presented the associated physics changes in detail. Here we present the model changes that are relevant for the SMB. The inclusion of a parameterization for cloud ice supersaturation (as described by Tompkins and others, 2007) results in more cloud water being transported towards the interior of the East Antarctic plateau, which decreases the negative bias in downward longwave radiation and surface temperature in RACMO2 (Van Wessem and others, 2014). Furthermore, the parameterizations describing the formation of precipitation have been changed by including an increase of the auto-conversion coefficient, which determines how quickly cloud content in convective clouds is converted into precipitation. This change leads to a more efficient and quicker formation of precipitation in convective situations. The coefficient was changed because updraft condensate was being overestimated in the previous ECMWF model runs (ECWMF, 2008). In addition, separate auto-conversion coefficients are introduced for ice and liquid-water clouds. For liquid-water clouds this coefficient is constant, while for ice clouds the coefficient decreases with temperature. This results in a more pronounced distinction between ice and liquid-water clouds (Lin and others, 1983).

\section{Observational data}

We evaluate the effects of the model changes on the SMB by comparing model output with observations. The observations include in situ SMB observations, ice surface velocities, GRACE satellite measurements and radar-derived accumulation.

We compare simulated SMB with 23500 in situ SMB measurements described by Favier and others (2013), originating from multiple sources of observations, ranging from ice cores and stake arrays to bomb horizons. Only the most reliable data ('A-rated' by Favier and others, 2013) are used and we omitted data covering time periods shorter than 10 years and data retrieved in areas of complex topography that are not resolved by the model (e.g. blue-ice areas in the Dry Valleys, and the Antarctic Peninsula (AP)), leaving 3234 in situ observations, shown in Figure 1. The use of this updated dataset improves on previous SMB evaluations by offering not only greater spatial coverage (cf. Lenaerts and others, 2012a) but also greater reliability (cf. Van de Berg and others, 2006), although it still leaves large areas devoid of data. To include a region with few in situ observations and to assess the spatial variance in SMB in more detail, we also use airborne-radar-derived accumulation in the Pine Island and Thwaites Glaciers area, West Antarctica (black box in Fig. 1) (Medley and others, 2013, 2014).

In addition to in situ SMB observations, we compare InSAR surface velocity observations (Rignot and others, 2011) with balance velocities, the latter computed using modelled SMB. This method assumes that the ice surface is stationary, resulting, for a given surface area, in a balance of mass in and out fluxes: $\nabla(V \mathbf{N} H)+\mathrm{SMB}=0$, where $V$ is the balance velocity, $\mathbf{N}$ is the observed velocity directions derived from satellite interferometry or surface slopes in the interior, ice thickness, $H$, is from Bedmap2 (Fretwell and others, 2013), and average SMB fields are from RACMO2.1 and RACMO2.3. This equation is solved for $V$ on a highresolution (three times ice thickness with a $3 \mathrm{~km}$ minimum) finite-element mesh, resulting in a velocity map for the Antarctic continent, that can be compared with InSAR surface velocities using radar interferometry (Rignot and others, 2011; Mouginot and others, 2012). Balance velocities are most accurate in areas where accumulation is low, due to significant errors near the ice-sheet margins (Bamber and others, 2000). However, InSAR velocities are less accurate in regions with low ice velocities, where difficulties arise in determining the flow direction. The 
comparison of the model with observations is therefore limited to regions where the error in the InSAR velocity is smaller than either the InSAR velocity itself (Mouginot and others, 2012) or the balance velocity. This criterion leaves large regions empty of data, most notably in West Antarctica and the coastal margins. As a result, the comparison is mostly limited to East Antarctica.

In addition to assessing the modelled spatial SMB variability by the two methods above, we evaluate the temporal SMB variability by comparing modelled SMB with mass change observations from the GRACE satellite mission (Tapley and others, 2004), using CSR RL05 data. To retrieve mass anomalies at a regional scale, we use the approach of Wouters and others (2008) and assign mass anomalies to predefined basins (using the definitions of Zwally and others, 2012) and adjust these until the difference between model and GRACE observations is minimized in a least-square sense. Originally developed for the Greenland ice sheet, this method was later adapted by King and others (2012) for the Antarctic ice sheet. Our approach follows that of King and others (2012), except that we do not apply their scaling factors to compensate for internal leakage. Instead, we subdivide the basins in a coastal zone $(<400 \mathrm{~km}$ from the grounded ice-sheet margin) and interior zone to better capture the pronounced variability in the marginal areas. We combined RACMO2.3 data with a hydrology model (GLDAS; Rodell and others, 2004) to create monthly GRACE pseudo-observations and find that our method captures the signal with a root-mean-square error of generally a few gigatonnes for the individual basins (included in the uncertainty). Uncertainties of the monthly observations are derived using the method of Wahr and others (2006). Furthermore, we compared the CSR data with two other GRACE releases (JPL RL05 and GFZ RL05a) and include the standard deviation of the differences in the uncertainties.

In this study, we focus on three regions using the basin definitions of Zwally and others (2012): Dronning Maud Land (basins 3-8; see Fig. 1), Terre Adélie and Wilkes Land (including Byrd Glacier basin) (basins 13-17) and West Antarctica (basins 1 and 18-23). The remaining basins have a large uncertainty in GRACE or are dominated by mass loss through glacier discharge, and are not used in the comparison. The linear trend is removed from GRACE to correct for glacial isostatic adjustment and calving fluxes, which are not included in RACMO2. Therefore, only the temporal variability associated with large precipitation events is accounted for (Wouters and others, 2013). In addition, a running average of 18 months is used to remove noise. To directly compare with GRACE, RACMO2 SMB is added cumulatively from 1979 to 2011, and both the long-term (1979-2011) and GRACE period (2003-11) linear trends are removed.

\section{RESULTS: CHANGES IN MODELLED SMB}

Here we discuss the changes in the modelled SMB and its components due to the update from RACMO2.1 to RACMO2.3.

\section{General SMB features}

To illustrate the general features of modelled Antarctic SMB, Figure 2 shows the annual mean (1979-2011) of the main SMB components, as simulated by RACMO2.3. Total precipitation peaks along the coastal margins, where the

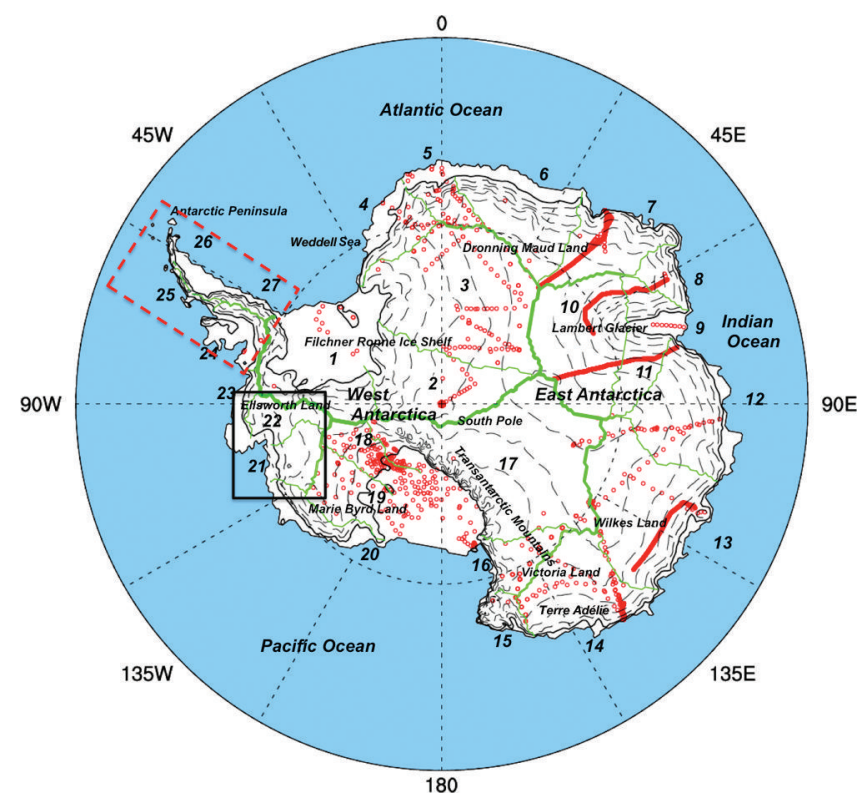

Fig. 1. Map of Antarctica showing 3234 in situ SMB observations (red circles) and 27 drainage basins (Zwally and others, 2012) (delineated by green lines) used in this study. The black box denotes a region which includes the Pine Island and Thwaites Glaciers area, used for comparison with a radar-derived accumulation map. The dashed red box denotes the region (the Antarctic Peninsula, north of $74^{\circ} \mathrm{S}$ ) that is excluded from calculations of integrated SMB. Regions referred to in the text: Dronning Maud Land (DML), Terre Adélie and Wilkes Land (AWL), Marie Byrd Land (MBL), Ellsworth Land (EL), the Antarctic Peninsula (AP) and the Filchner-Ronne Ice Shelf (FRIS). Also shown are the ice-shelf edge and grounding line (solid black curves) and height intervals every $500 \mathrm{~m}$ (dashed black curves) based on a digital elevation model of Liu and others (2001), as used in RACMO2.

terrain is steep, the air still relatively warm and humid, and precipitation mostly orographically forced. In West Antarctica and the AP, where elevation gradients are large and the onshore flow most pronounced, precipitation rates are highest. The interior of the ice sheet is dry, with precipitation generally $<50 \mathrm{~mm}$ w.e. $\mathrm{a}^{-1}$ above $3000 \mathrm{~m}$ a.s.l.

Figure $2 \mathrm{~b}$ shows that sublimation, largely through sublimation of drifting snow (Lenaerts and Van den Broeke, 2012), also peaks in the steep escarpment region, where wind speed is highest. However, quantities are typically an order of magnitude smaller than precipitation. Snowmelt (Fig. 2c) is also largest along the coastal margins and peaks over the ice shelves in the AP. However, in the model nearly all meltwater is refrozen and/or retained in the snowpack, so meltwater runoff is essentially zero. Figure $2 \mathrm{~d}$ shows the resulting $\mathrm{SMB}$; the pattern is very similar to that of total precipitation, stressing the dominance of precipitation over the other SMB components.

The model distinguishes between convective and largescale precipitation. Table 1 shows that the grounded ice sheet integrated SMB (excluding the AP) is dominated by large-scale snowfall ( $97 \%$ of total precipitation versus $2.6 \%$ for convective precipitation and $<0.1 \%$ for rain). Driftingsnow sublimation removes $\sim 8 \%$ of snowfall, compared with only $\sim 2 \%$ by surface sublimation, while drifting-snow erosion is essentially zero (not shown) when integrated over large regions (Lenaerts and others, 2012a). Comparisons with observed drifting snow in Greenland suggest that RACMO2.3 somewhat overestimates ER ds $_{\text {locally (Lenaerts }}$ and others, 2014). As a mass loss term, runoff is negligible. 

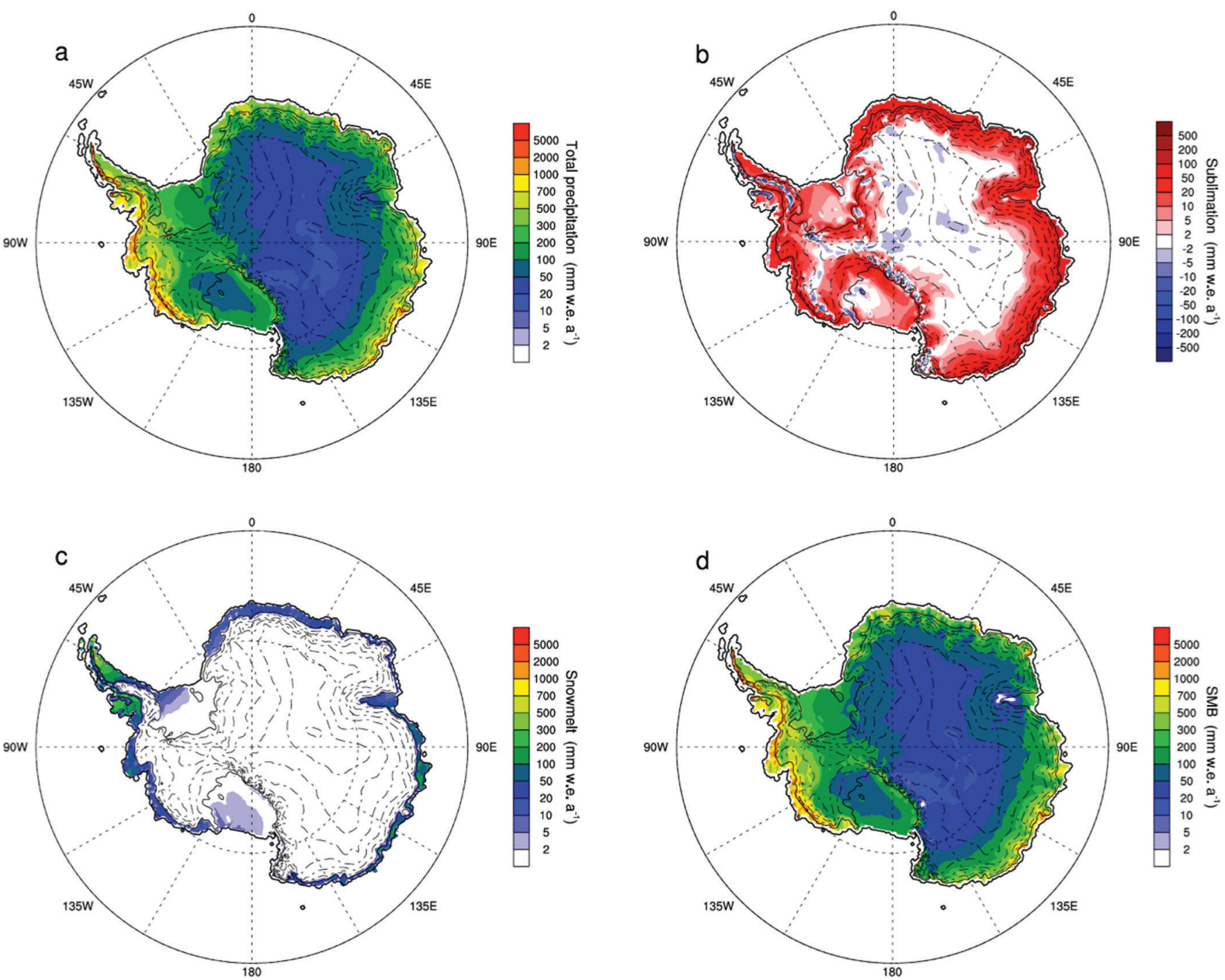

Fig. 2. RACMO2.3 annual means (1979-2011) of (a) total precipitation, (b) total (surface and snowdrift) sublimation, (c) snowmelt and (d) SMB.

\section{Changes in SMB components}

Figure 3 shows the difference between the average (19792011) SMB components from RACMO2.3 and RACMO2.1. Figure 3a shows considerable increases of total precipitation in the interior of East Antarctica, most notably in Dronning Maud Land (DML), the AP and the Filchner-Ronne Ice Shelf (FRIS). Along the coastline of Marie Byrd Land (MBL) and Terre Adélie and Wilkes Land (AWL) there is a decrease $\left(<-20 \mathrm{~mm}\right.$ w.e. $\left.\mathrm{a}^{-1}\right)$ in precipitation. Integrated over the grounded ice sheet (excluding the AP) (Table 1), this results in a precipitation increase of $40 \mathrm{Gta}^{-1}(+2.1 \%)$ in RACMO2.3 compared to RACMO2.1. Table 1 shows that snowfall has increased by $45 \mathrm{Gta}^{-1}(+2.3 \%)$, dominating the increase in total precipitation. The difference of $5 \mathrm{Gta}^{-1}$ is explained by a decrease in rainfall $(-83 \%)$, due to the changed distinction of auto-conversion coefficients between ice and liquid-water clouds. Convective precipitation along the entire coastline of Antarctica has increased considerably, by $39 \mathrm{Gta}^{-1}(+325 \%)$. This increase is due to the increase of the auto-conversion coefficient for convective precipitation, together with changes in the turbulence scheme. The pattern of changes in total precipitation is dominated by changes in large-scale precipitation, which, despite being negligible overall, are often two orders of magnitude larger than changes in convective precipitation. The changes in largescale precipitation vary considerably on a local scale, but in total it has increased by only $1 \mathrm{Gta}^{-1}(<0.1 \%)$.

The changes in sublimation between RACMO2.3 and RACMO2.1 (Fig. 3b) are dominated by changes in driftingsnow sublimation (Fig. $3 \mathrm{~d}$ ). In the escarpment region, $\mathrm{SU}_{\mathrm{ds}}$ has decreased. Towards the interior of the East Antarctic ice sheet, deposition (riming) dominates, and has increased slightly in RACMO2.3, due to increased temperatures (Van Wessem and others, 2014) and, therefore, moister conditions. This results in a net decrease in total sublimation of $6 \mathrm{Gta}^{-1}(-3.3 \%)$.

Figure 3c shows a widespread decrease in melt in RACMO2.3, by a total of $6 \mathrm{Gta}^{-1}(-35 \%)$. The differences are most pronounced over the ice shelves fringing East Antarctica. Because of the decrease in rain and melt, refreezing has decreased by $14 \mathrm{Gta}^{-1}(-56 \%)$.

\section{Resulting changes in SMB}

The sum of the changes in individual SMB components leads to the change of the modelled SMB (Fig. 4), which mainly reflects changes in solid precipitation. Two large-scale patterns of changes, which are superimposed, can be distinguished. First, there is a general decrease in coastal 
precipitation and an increase in interior precipitation. Second, strong regional deviations occur in response to changes in large-scale atmospheric circulation. As a combined result, the following regional changes are found (the stippled pattern in Fig. 4 denotes areas where changes are larger than the interannual variability of the difference): $\mathrm{SMB}$ on the East Antarctic plateau and at DML has increased by up to $50 \%$, while $\mathrm{SMB}$ has decreased in the coastal region of $A W L$ by up to $\sim 250 \mathrm{mmw}^{-e . \mathrm{a}^{-1}}(-15 \%)$, and in coastal MBL by up to $200 \mathrm{~mm}$ w.e. $\mathrm{a}^{-1}(-10 \%)$. In particular, the changes in DML and on the East Antarctic plateau exceed the interannual variability, while changes in $\mathrm{MBL}$ only locally exceed the interannual variability.

Circulation changes have modified the general SMB patterns, mainly in West Antarctica, the AP and DML. The $\mathrm{SMB}$ on the AP has been redistributed, with an increase on the windward (western) side and a decrease on the lee side of the mountain ridge, as well as on the eastern ice shelves. The AP SMB is not discussed in further detail here, as we deem the model resolution too low for this topographically rough region. In the coastal and escarpment region of $\mathrm{DML}, \mathrm{SMB}$ has increased by $\sim 100 \mathrm{~mm}$ w.e. $\mathrm{a}^{-1}$, or up to $30 \%$. Integrated over the grounded ice sheet (excluding the AP) (Table 1), the SMB has increased from $1748 \mathrm{Gta}^{-1}(\sigma=$ $\left.98 \mathrm{Gta}^{-1}\right)$ in RACMO2.1 to $1793 \mathrm{Gta}^{-1}\left(\sigma=106 \mathrm{Gta}^{-1}\right)$ in RACMO2.3, an increase of $45 \mathrm{Gta}^{-1}(+2.5 \%)$ with an uncertainty due to the interannual variability of the difference of $11 \mathrm{Gt} \mathrm{a}^{-1}$. Moreover, while regionally strong, the increase of $2.5 \%$ is within the uncertainty calculated for RACMO2.1 of 8\% (Lenaerts and others, 2012a). Using the basin definitions of Zwally and others (2012), the SMB for the East Antarctic (basins 2-17) and West Antarctic (basins 1 and 18-23) ice sheets has increased by 44 and $0.5 \mathrm{Gta}^{-1}$ respectively.

The redistribution of precipitation from the coastal zones to the interior ice sheet in East Antarctica is mainly caused by the new parameterization of ice cloud supersaturation, allowing supersaturation and, hence, the transport of more water vapour onto the ice sheet. The $500 \mathrm{hPa}$ circulation patterns in Figure 4 suggest that the deviating pattern in DML is caused by a stronger northerly circulation, transporting more moist air from the South Atlantic Ocean onto the ice sheet between 0 and $45^{\circ} \mathrm{E}$. Stronger onshore winds also explain the SMB increase on the FRIS and in the adjacent area towards the South Pole, where more precipitating clouds are advected onto the ice sheet. Between these areas, wind anomalies are directed off the ice sheet, and precipitation has decreased. Similar reasoning applies to coastal West Antarctica and Ellsworth Land (EL), where increased westerlies have enhanced the precipitation shadowing effect, increasing SMB on the windward side and decreasing it on the lee side.

\section{RESULTS: COMPARISON OF MODEL CHANGES WITH OBSERVATIONS}

In order to assess whether the changes have actually improved the model results, we compare the SMB fields (1979-2011 mean) with available observations.

\section{In situ observations}

Figure 5 presents the absolute and relative bias (modelobservation) of the SMB as a function of surface elevation for 3234 in situ observations (Favier and others, 2013). Most
Table 1. Grounded ice sheet integrated SMB mean values $\left(\mathrm{Gt} \mathrm{a}^{-1}\right)$ with interannual variability, $\sigma$. Total (snow + rain) precipitation (PR), snowfall, rainfall, convective precipitation (PRC), large-scale precipitation (PRLS), total sublimation $\left(\mathrm{SU}_{\text {tot }}\right)$, surface sublimation $\left(\mathrm{SU}_{\mathrm{s}}\right)$, snowdrift sublimation $\left(\mathrm{SU}_{\mathrm{ds}}\right)$, runoff $(\mathrm{RU})$, snowmelt $(\mathrm{M})$ and refrozen mass (RF). All values represent the grounded ice sheet excluding the Antarctic Peninsula, where the model has insufficient horizontal resolution. Also given are the integrated SMB values (based on the basin definitions of Zwally and others, 2012) for the grounded ice sheets of East Antarctica (EAIS, basins 2-17) and West Antarctica (WAIS, basins 1 and 18-23).

\begin{tabular}{lrrrrc}
\hline & \multicolumn{2}{c}{ RACMO2.3 } & \multicolumn{2}{c}{ RACMO2.1 } & $\begin{array}{c}\text { RACMO2.3 } \\
\text { RACMO2.1 }\end{array}$ \\
& \multicolumn{1}{c}{ mean } & $\sigma$ & mean & $\sigma$ & mean \\
& & & & & \\
\hline PR & 1970 & 107 & 1930 & 99 & $+40(2.1 \%)$ \\
Snowfall & 1969 & 107 & 1924 & 96 & $+45(2.3 \%)$ \\
Rainfall & 1 & 0.1 & 6 & 3 & $-5(83 \%)$ \\
PRC & 51 & 6 & 12 & 2 & $+39(325 \%)$ \\
PRLS & 1921 & 101 & 1921 & 99 & $+1(<0.1 \%)$ \\
$\mathrm{SU}_{\text {tot }}$ & 176 & 9 & 182 & 9 & $-6(3.3 \%)$ \\
$\mathrm{SU}_{\mathrm{s}}$ & 24 & 1 & 28 & 1 & $-4(14 \%)$ \\
$\mathrm{SU}_{\mathrm{ds}}$ & 153 & 8 & 154 & 8 & $-1(0.6 \%)$ \\
$\mathrm{RU}$ & 0 & 0 & 0 & 0 & 0 \\
$\mathrm{M}$ & 11 & 6 & 17 & 8 & $-6(35 \%)$ \\
$\mathrm{RF}$ & 11 & 6 & 25 & 9 & $-14(56 \%)$ \\
$\mathrm{SMB}$ & 1793 & 106 & 1748 & 98 & $+45(2.5 \%)$ \\
$\mathrm{SMB}$ (EAIS) & 1096 & 92 & 1052 & 78 & $+44(4.2 \%)$ \\
$\mathrm{SMB}$ (WAIS) & 600 & 58 & 599 & 71 & $+0.5(<0.1 \%)$ \\
& & & & &
\end{tabular}

SMB observations originate from sites in relatively dry areas of the ice sheet, while only a few SMB measurements are available from high-accumulation regions (Fig. 1). The clustering of observations (e.g. near the Ross Ice Shelf) results in an over-representation of some areas, and an underrepresentation of others. At the same time, the reliability of a regional value is greater when the observational density is large. Taking all this into account, an uncertainty is assigned to each observation, following the method of Van de Berg and others (2006). Direct comparison of observations with modelled SMB (not shown here; fig. 2 of Lenaerts and others, 2012a) does not show a significant change. The correlation of modelled RACMO2.3 SMB with the observations $\left(r^{2}=0.77\right)$ remains similar to that of RACMO2.1, and to the correlation with the old dataset, as found by Lenaerts and others (2012a). However, when all observations are binned in nine surfaceelevation classes (at $500 \mathrm{~m}$ intervals) to compensate for the clustering, a clear change can be seen.

Figure 5a shows that RACMO2.1 SMB is too low in almost all elevation classes, indicating that the model is generally too dry. In particular, the bins above $2000 \mathrm{~m}$, which all originate from the East Antarctic plateau, are too dry by $20-55 \%$ (Fig. 5b). RACMO2.3 SMB values show smaller biases except for the 1000-2000m bins. These elevation classes represent the coastal escarpment, where SMB observations are scarce and uncertainties are large and overlapping. Changes are small for the 500 and $2000 \mathrm{~m}$ bins.

For East Antarctica $(>2000 \mathrm{~m})$ the absolute and relative biases have been largely removed. For the coastal bin (0$250 \mathrm{~m}$ ) the bias has also decreased, and the improvement is significant. This height bin mainly contains observations from the Filchner-Ronne and Ross Ice Shelves, which are wetter in RACMO2.3. 

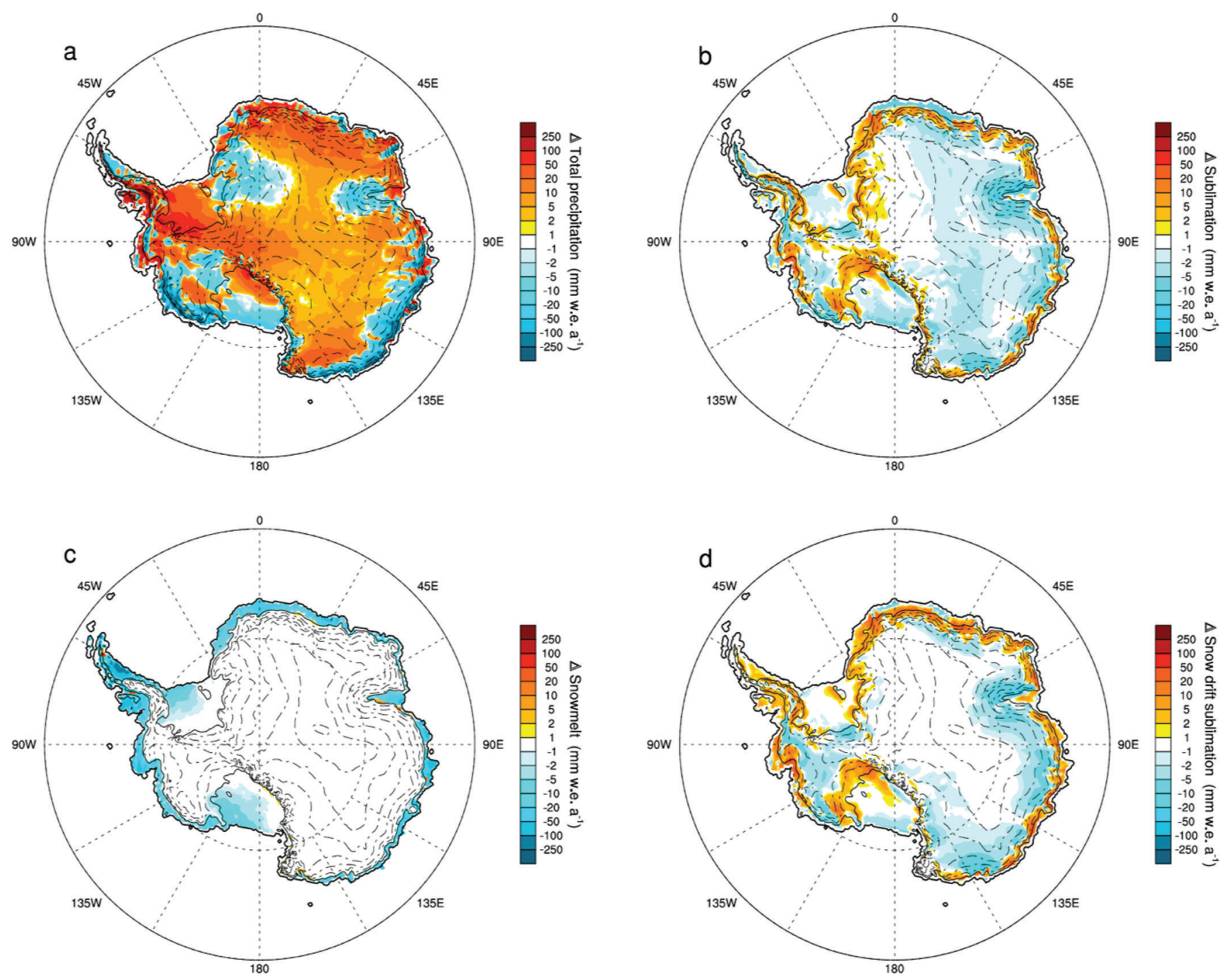

Fig. 3. Annual mean (1979-2011) difference (RACMO2.3 - RACMO2.1) of (a) total precipitation, (b) total (surface and drifting snow) sublimation, (c) snowmelt and (d) snowdrift sublimation.

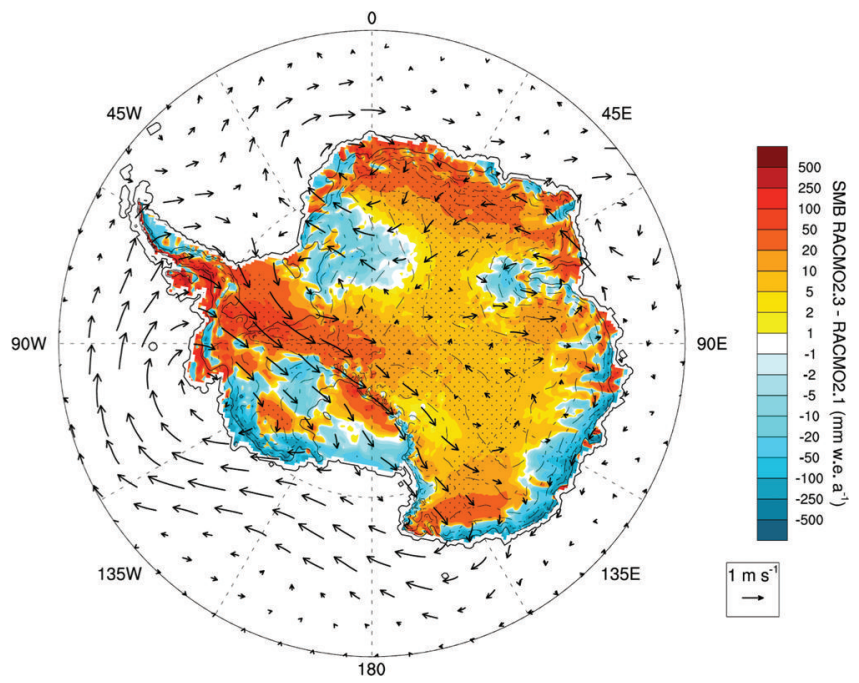

Fig. 4. Average (1979-2011) SMB difference (RACMO2.3RACMO2.1). Vectors show direction and magnitude of average $500 \mathrm{hPa}$ wind speed difference (RACMO2.3-RACMO2.1) $\left(\mathrm{m} \mathrm{s}^{-1}\right)$. Areas where the difference exceeds one unit of standard deviation of the difference are stippled.

\section{Radar observations in West Antarctica}

We also compared modelled SMB with radar-derived accumulation in the Pine Island and Thwaites Glaciers area (Fig. 1). These results are discussed by Medley and others (2014), who showed that RACMO2.1 performs well in terms of spatial variability. After further comparison with RAC$\mathrm{MO} 2.3$, the model ability to capture spatial variability remains unchanged (correlation $r^{2}=0.83$ ). Although minor, this is a reduction of the overall bias (model-observation) in the 1985-2009 mean annual SMB: the root-mean-square error decreases from $-4.1 \%$ in $\mathrm{RACMO} 2.1$ to $-3.0 \%$ in RACMO2.3 (not shown).

\section{Balance velocities}

An original application of balance ice velocities (Bamber and others, 2000) is to assess the quality of modelled SMB fields, by comparing them with observed surface velocities from InSAR (Rignot and others, 2011; Mouginot and others, 2012) (Fig. 6a). Figure $6 \mathrm{~b}$ and $\mathrm{c}$ show the relative difference of the InSAR ice velocity with the balance velocity computed using SMB from RACMO2.1 and RACMO2.3, respectively. In line with the comparison with in situ SMB observations, a considerable improvement is found in East 

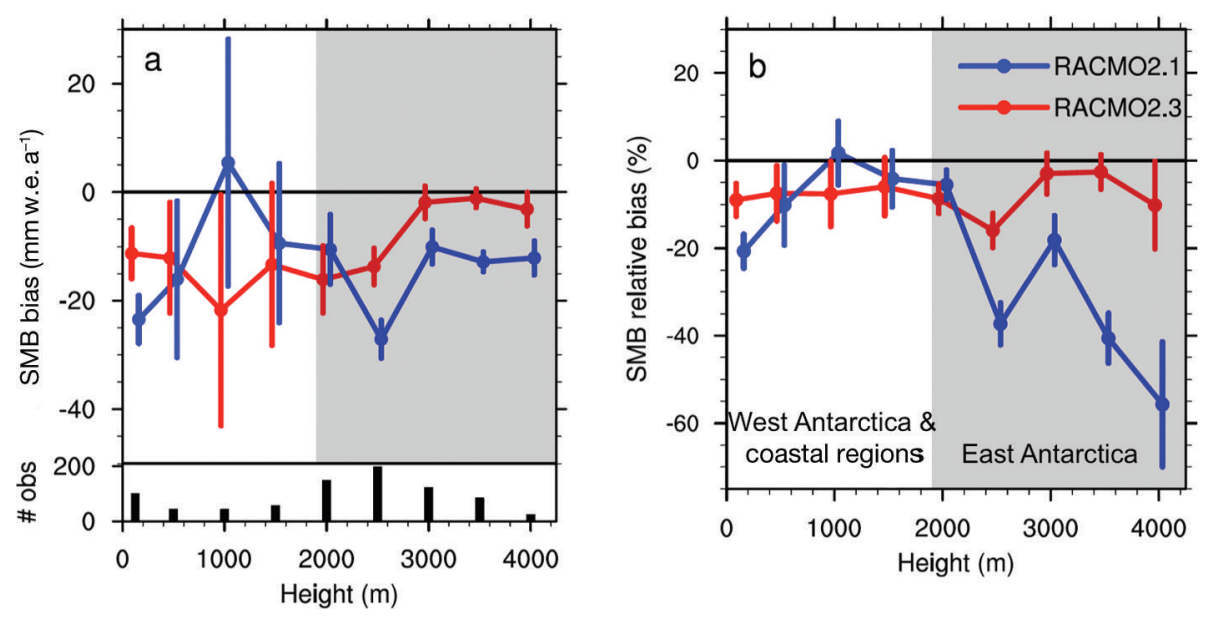

Fig. 5. (a) Absolute bias and (b) relative bias ((model-observation)/(model $\times 100 \%)$ ) in modelled SMB for RACMO2.1 (blue) and RACMO2.3 (red). The data are binned in $500 \mathrm{~m}$ surface elevation intervals (0-250, 250-750 m, etc.). Error bars denote the combined uncertainty of the model and observations in each height bin, based on Van de Berg and others (2006). Elevations above $2000 \mathrm{~m}$ (shaded grey) represent East Antarctica exclusively. The bar chart in (a) denotes the amount of weighted observations in each bin. To separate blue and red lines, $x$-axis locations of each bin are displaced by $75 \mathrm{~m}$.
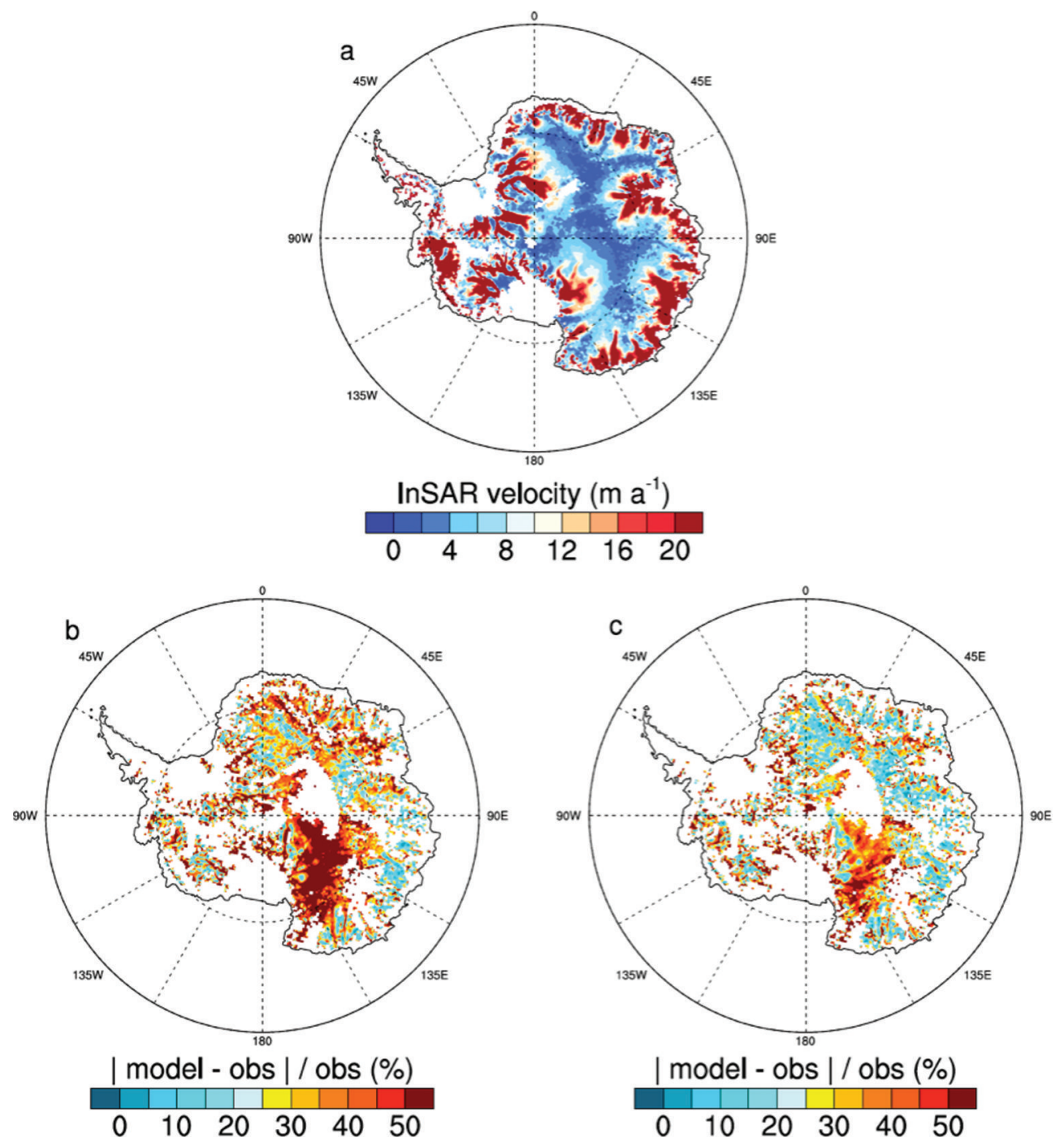

Fig. 6. (a) Ice surface velocity from InSAR. (b, c) Relative difference magnitude between InSAR and balance velocities computed using (b) RACMO2.1 and (c) RACMO2.3 SMB fields. Regions where uncertainties in either balance velocity or InSAR velocity are large are not included in the comparison. These include regions of low velocity near the ice divide in East Antarctica and coastal regions, and parts of West Antarctica where high accumulation rates cause correlation problems between different InSAR images. All data have been interpolated to the RACMO grid. 

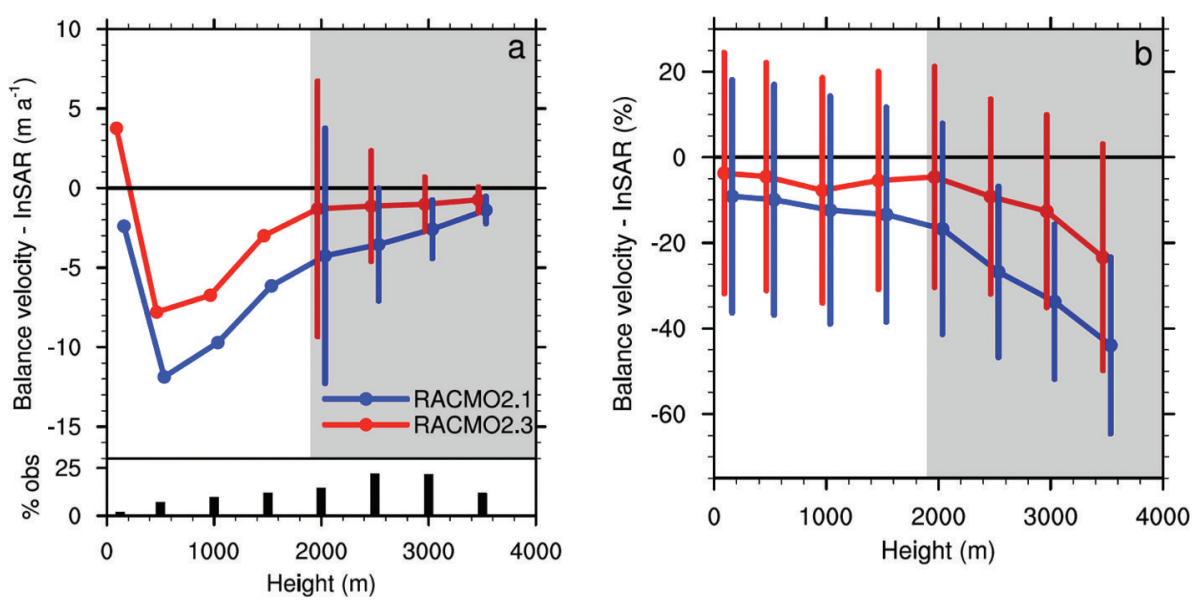

Fig. 7. (a) Absolute bias and (b) relative bias ((model-observation)/(model $\times 100 \%)$ ) and bias standard deviation (error bars) between InSAR and balance velocity computed using SMB from RACMO2.3 (red) and RACMO2.1 (blue). The data are binned in nine $500 \mathrm{~m}$ surface elevation intervals (0-250, 250-750 m, etc.). Elevations above $2000 \mathrm{~m}$ (shaded grey) represent East Antarctica. The bar chart in (a) denotes percentage of total gridpoints per elevation bin, after filtering of data, as explained in the Data and Methods section. The final height bin $(3750-4250 \mathrm{~m})$ is omitted, due to limited data points $(<50)$ in the bin. To separate blue and red lines, $x$-axis locations of each bin are separated by $75 \mathrm{~m}$; standard deviations for the first four bins in (a) are so large that they are not plotted, for clarity.

Antarctica, especially in DML, the FRIS and the Lambert Glacier basin. In the Byrd Glacier basin, differences have become smaller but are still substantial ( 40\%). In West Antarctica, no considerable changes are seen, in agreement with the previous subsection.

Figure 7 shows the bias and relative bias (error bars denote bias standard deviation) of the balance velocity with respect to the InSAR velocity, binned in eight surfaceelevation intervals, and filtered as in Figure 6. When compared with InSAR, both model SMB fields have lower balance velocities in all bins, indicative of underestimated $\mathrm{SMB}$, in line with Figure 5. Part of this underestimation $(5-10 \%)$ is because the balance velocities are depthaveraged, and InSAR velocities are surface velocities. For RACMO2.3, the balance velocity has improved in all bins. In agreement with Figure 5, this implies an improvement in the RACMO2.3 SMB field relative to RACMO2.1, especially in interior East Antarctica.

\section{GRACE}

The previous sections dealt with spatial SMB variability. Temporal SMB variability, mainly representing precipitation events, can be compared with GRACE satellite retrievals (Horwath and Dietrich, 2009; Wouters and others, 2013). Figure 8 shows the detrended mass anomalies for three regions: DML, AWL (including Byrd Glacier basin) and West Antarctica. In general, there is reasonable agreement between model and GRACE temporal variability (Shepherd and others, 2012; Wouters and others, 2013). For DML, agreement is strong and RACMO2.3 shows no significant change in representing the $S M B$ variability. For $A W L$, the timing of the maximum accumulation in 2007, and the minimum in 2008, is good, but the amplitude is off. For West Antarctica, temporal variability is well simulated by both model versions, although the amplitude is underestimated, but no significant change is found. We conclude that with respect to temporal variability, no significant improvements are seen between RACMO2.1 and RACMO2.3; all changes fall within the combined uncertainties of the model and GRACE.

\section{SUMMARY AND CONCLUSIONS}

The physics package of the regional atmospheric climate model RACMO2 has been updated from RACMO2.1 to RACMO2.3. A recent study by Van Wessem and others (2014) demonstrated improvements of the simulated SEB. The present study shows similar improvements of the SMB of Antarctica; RACMO2.3 simulates considerably wetter conditions in the interior of East Antarctica. The SMB in RACMO2.3, integrated over the grounded ice sheet (excluding the AP), increased to $1793 \mathrm{Gt} \mathrm{a}^{-1}$ (with interannual variability $\sigma=106 \mathrm{Gt} \mathrm{a}^{-1}$ ), an increase of $45 \mathrm{Gta}^{-1}$ (2.5\%) (with an uncertainty due to interannual variability of $11 \mathrm{Gta}^{-1}$ ) when compared with RACMO2.1, in particular over the grounded ice sheet of East Antarctica $\left(+44 \mathrm{Gta}^{-1}\right)$. This increase is dominated by an increase in snowfall of $+45 \mathrm{Gt} \mathrm{a}^{-1}$, partly compensated by decreased rainfall; other SMB components show small changes. The increase in precipitation is a combined result of the inclusion of ice cloud supersaturation in the model, resulting in increased cloud cover over the interior ice sheet, a redistribution of snowfall from the coast to the interior, and regional changes associated with changes in the large-scale circulation patterns. The change in SMB is evaluated using various available observations:

A comparison with 3234 in situ SMB observations (Favier and others, 2013) shows a considerable improvement of RACMO2.3 over RACMO2.1 for the dry East Antarctic plateau, where biases are almost completely removed. The low-lying coastal regions show smaller changes, which mostly fall within the combined uncertainty of model and observations.

A comparison of modelled SMB with a radar-derived accumulation map, for the Thwaites and Pine Island Glaciers area (Medley and others, 2014), indicates that spatial variability in this relatively wet area, which was already well represented in RACMO2.1, has improved further in RACMO2.3.

Modelled SMB fields are used to compute balancevelocity fields for the Antarctic continent, which are 

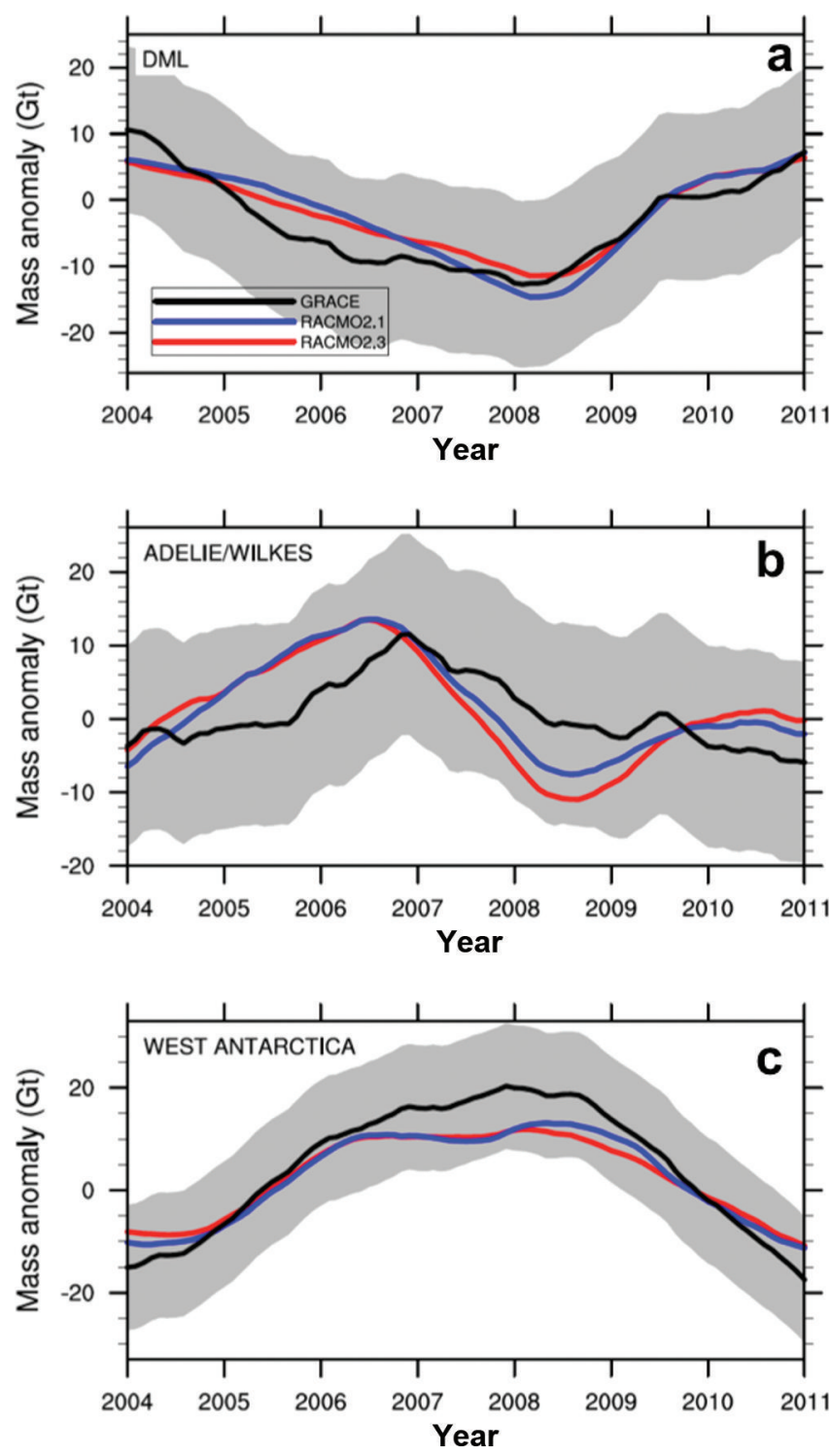

Fig. 8. Detrended and 18 month running average SMB anomalies of RACMO2.3, RACMO2.1 and GRACE release RL05 for three regions of Antarctica: (a) Dronning Maud Land (basins 3-8), (b) Terre Adélie and Wilkes Land (including Byrd Glacier basin) (basins 13-17) and (c) West Antarctica (basins 1 and 18-23). Uncertainty of GRACE (one standard deviation) is shaded grey.

compared with InSAR ice surface velocities (Mouginot and others, 2012). Using SMB from RACMO2.3 shows a strong improvement over RACMO2.1 in interior East Antarctica. Although improved, a substantial bias remains in the Byrd Glacier basin. Changes in West Antarctica are small. These results are in line with the two observations listed above.

A comparison of SMB temporal variability with detrended GRACE (Tapley and others, 2004) time series shows no significant improvement.

This study shows that for East Antarctica the modelled SMB in RACMO2.3 improves considerably on the previous RAC$\mathrm{MO} 2.1$ product, but is within previous model uncertainty estimates (Lenaerts and others, 2012a). For West Antarctica, and especially the AP, more observational data and higherresolution climate modelling are needed to enable similar comparisons. A high-resolution run $(\sim 5.5 \mathrm{~km})$ is currently being performed for the AP.

\section{ACKNOWLEDGEMENTS}

We are grateful for the financial support of NWO/ALW, Netherlands Polar Programme. J.L.B. was funded by the UK Natural Environment Research Council grant NE/I027401/1. We thank the ECMWF for use of their supercomputing facilities.

\section{REFERENCES}

Bamber JL, Hardy RJ and Joughin I (2000) An analysis of balance velocities over the Greenland ice sheet and comparison with synthetic aperture radar interferometry. J. Glaciol., 46(152), 67-74 (doi: 10.3189/172756500781833412)

Borsa AA, Moholdt G, Fricker HA and Brunt KM (2014) A range correction for ICESat and its potential impact on ice-sheet mass balance studies. Cryosphere, 8(2), 345-357 (doi: 10.5194/tc-8345-2014)

Bromwich DH, Guo Z, Bai L and Chen Q (2004) Modelled Antarctic precipitation. Part I: spatial and temporal variability. J. Climate, 17(3), 427-447 (doi: 10.1175/1520-0442(2004)017<0427: MAPPIS>2.0.CO;2)

Dee DP and 35 others (2011) The ERA-Interim reanalysis: configuration and performance of the data assimilation system. Q. J. R. Meteorol. Soc., 137(656), 553-597 (doi: 10.1002/qj.828)

Ettema J, Van den Broeke MR, Van Meijgaard E, Van de Berg WJ, Box JE and Steffen K (2010) Climate of the Greenland ice sheet using a high-resolution climate model: Part 1: evaluation. Cryosphere, 4(4), 511-527 (doi: 10.5194/tc-4-511-2010)

European Centre for Medium-Range Weather Forecasts (ECMWF) (2008) IFS Documentation - CY33R1. Part IV: physical processes. European Centre for Medium-Range Weather Forecasts, Reading

Favier V and 8 others (2013) An updated and quality controlled surface mass balance dataset for Antarctica. Cryosphere, 7(2), 583-597 (doi: 10.5194/tc-7-583-2013)

Fettweis X, Tedesco M, Van den Broeke M and Ettema J (2011) Melting trends over the Greenland ice sheet (1958-2009) from spaceborne microwave data and regional climate models. Cryosphere, 5(2), 359-375 (doi: 10.5194/tc-5-359-2011)

Fretwell P and 59 others (2013) Bedmap2: improved ice bed, surface and thickness datasets for Antarctica. Cryosphere, 7(1), 375-393 (doi: 10.5194/tc-7-375-2013)

Greuell JW and Konzelmann T (1994) Numerical modeling of the energy balance and the englacial temperature of the Greenland ice sheet: calculations for the ETH-Camp location (West Greenland, $1155 \mathrm{~m}$ a.s.l.). Global Planet. Change, 9(1-2), 91-114

Gunter B and 8 others (2009) A comparison of coincident GRACE and ICESat data over Antarctica. J. Geod., 83(11), 1051-1060 (doi: 10.1007/s00190-009-0323-4)

Horwath M and Dietrich R (2009) Signal and error in mass change inferences from GRACE: the case of Antarctica. Geophys. J. Int., 177(3), 849-864 (doi: 10.1111/j.1365-246X.2009.04139.x)

King MA, Bingham RJ, Moore P, Whitehouse PL, Bentley MJ and Milne GA (2012) Lower satellite-gravimetry estimates of Antarctic sea-level contribution. Nature, 491(7425), 586-589 (doi: 10.1038/nature11621)

Kuipers Munneke P, Van den Broeke MR, Lenaerts JTM, Flanner MG, Gardner AS and Van de Berg WJ (2011) A new albedo parameterization for use in climate models over the Antarctic ice sheet. J. Geophys. Res., 116(D5), D05114 (doi: 10.1029/ 2010JD015113)

Lenaerts JTM and Van den Broeke MR (2012) Modeling drifting snow in Antarctica with a regional climate model: 2. Results. J. Geophys. Res., 117(D5), D05109 (doi: 10.1029/ 2010JD015419)

Lenaerts JTM, Van den Broeke MR, Van de Berg WJ, Van Meijgaard E and Kuipers Munneke P (2012a) A new, high-resolution surface mass balance map of Antarctica (1979-2010) based on 
regional atmospheric climate modeling. Geophys. Res. Lett., 39(4), L04501 (doi: 10.1029/2011GL050713)

Lenaerts JTM, Van den Broeke MR, Scarchilli C and Agosta C (2012b) Impact of model resolution on simulated wind, drifting snow and surface mass balance in Terre Adélie, East Antarctica. J. Glaciol., 58(211), 821-829 (doi: 10.3189/2012JoG12J020)

Lenaerts JTM and 6 others (2012c) Modeling drifting snow in Antarctica with a regional climate model: 1 . Methods and model evaluation. J. Geophys. Res., 117(D5), D05108 (doi: 10.1029/ 2011JD016145)

Lenaerts JTM, Van Angelen JH, Van den Broeke MR, Gardner AS, Wouters B and Van Meijgaard E (2013) Irreversible mass loss of Canadian Arctic Archipelago glaciers. Geophys. Res. Lett., 40(5), 870-874 (doi: 10.1002/grl.50214)

Lenaerts JTM and 6 others (2014) Drifting snow measurements on the Greenland Ice Sheet and their application for model evaluation. Cryos. Discuss., 8(1), 21-53 (doi: 10.5194/tcd-8-21-2014)

Ligtenberg SRM, Horwath M, Van den Broeke MR and Legrésy B (2012) Quantifying the seasonal 'breathing' of the Antarctic ice sheet. Geophys. Res. Lett., 39(23), L23501 (doi: 10.1029/ 2012GL053628)

Lin Y-L, Farley RD and Orville HD (1983) Bulk parameterization of the snow field in a cloud model. J. Climate Appl. Meteorol., 22(6), 1065-1092 (doi: 10.1175/1520-0450(1983)022)

Liu H, Jezek K, Li B and Zhao Z (2001) Radarsat Antarctic mapping project digital elevation model Version 2. National Snow and Ice Data Center, Boulder, CO. Digital media: http://nsidc.org/ data/nsidc-0082.html

Medley B and 12 others (2013) Airborne-radar and ice-core observations of annual snow accumulation over Thwaites Glacier, West Antarctica confirm the spatiotemporal variability of global and regional atmospheric models. Geophys. Res. Lett., 40(14), 3649-3654 (doi: 10.1002/grl.50706)

Medley B and 14 others (2014) Constraining the recent mass balance of Pine Island and Thwaites glaciers, West Antarctica with airborne observations of snow accumulation. Cryos. Discuss., 8(1), 953-998 (doi: 10.5194/tcd-8-953-2014)

Mouginot J, Scheuchl B and Rignot E (2012) Mapping of ice motion in Antarctica using synthetic-aperture radar data. Remote Sens., 4(9), 2753-2767 (doi: 10.3390/rs4092753)

Reijmer CH, Van Meijgaard E and Van den Broeke MR (2005) Evaluation of temperature and wind over Antarctica in a Regional Atmospheric Climate Model using 1 year of automatic weather station data and upper air observations. J. Geophys. Res., 110(D4), D04103 (doi: 10.1029/2004JD005234)

Rignot E and 6 others (2008) Recent Antarctic ice mass loss from radar interferometry and regional climate modelling. Nature Geosci., 1(2), 106-110 (doi: 10.1038/ngeo102)

Rignot E, Mouginot J and Scheuchl B (2011) Ice flow of the Antarctic Ice Sheet. Science, 333(6048), 1427-1430 (doi: 10.1126/science.1208336)

Rodell M and 6 others (2004) Basin scale estimates of evapotranspiration using GRACE and other observations. Geophys. Res. Lett., 31(20), L20504 (doi: 10.1029/2004GL020873)
Shepherd A and 46 others (2012) A reconciled estimate of ice-sheet mass balance. Science, 338(6111), 1183-1189 (doi: 10.1126/ science.1228102)

Tapley BD, Bettardpur S, Watkins M and Reigber C (2004) The Gravity Recovery and Climate Experiment: mission overview and early results. Geophys. Res. Lett., 31(6), L09607 (doi: 10.1029/2004GL019920)

Tompkins AM, Gierens K and Rädel G (2007) Ice supersaturation in the ECMWF integrated forecast system. Q. J. R. Meteorol. Soc., 133(622), 53-63 (doi: 10.1002/qj.14)

Undén P and 26 others (2002) The high resolution limited area model. HIRLAM-5 scientific documentation. (Technical Report) Swedish Meteorological and Hydrological Institute, Norrköping

Van Angelen JH, Lenaerts JTM, Van den Broeke MR, Fettweis X and Van Meijgaard E (2013) Rapid loss of firn pore space accelerates 21 st century Greenland mass loss. Geophys. Res. Lett., 40(10), 2109-2113 (doi: 10.1002/grl.50490)

Van de Berg WJ, Van den Broeke MR, Reijmer $\mathrm{CH}$ and Van Meijgaard E (2005) Characteristics of the Antarctic surface mass balance, 1958-2002, using a regional atmospheric climate model. Ann. Glaciol., 41, 97-104 (doi: 10.3189/172756405781813302)

Van de Berg WJ, Van den Broeke MR, Reijmer $\mathrm{CH}$ and Van Meijgaard E (2006) Reassessment of the Antarctic surface mass balance using calibrated output of a regional atmospheric climate model. J. Geophys. Res., 111(D11), D11104 (doi: 10.1029/2005JD006495)

Van Lipzig NPM, King JC, Lachlan-Cope T and Van den Broeke MR (2004) Precipitation, sublimation, and snow drift in the Antarctic Peninsula region from a regional atmospheric model. J. Geophys. Res., 109(D24), D24106 (doi: 10.1029/2004JD004701)

Van Meijgaard E and 6 others (2012) Refinement and application of a regional atmospheric model for climate scenario calculations of Western Europe. (Final Report, National Research Programme Climate Changes Spatial Planning KvR 054/12) Royal Netherlands Meteorological Institute, Nieuwegein

Van Wessem JM, Reijmer CH, Lenaerts JTM, Van de Berg WJ, Van den Broeke MR and Van Meijgaard E (2014) Updated cloud physics in a regional atmospheric climate model improves the modelled surface energy balance of Antarctica. Cryosphere, 8(1), 125-135 (doi: 10.5194/tc-8-125-2014)

Wahr J, Swenson S and Velicogna I (2006) Accuracy of GRACE mass estimates. Geophys. Res. Lett., 33(6), L06401 (doi: 10.1029/2005GL025305)

Wouters B, Chambers D and Schrama EJO (2008) GRACE observes small-scale mass loss in Greenland. Geophys. Res. Lett., 35(2), L20501 (doi: 10.1029/2008GL034816)

Wouters B, Bamber JL, Van den Broeke MR, Lenaerts JTM and Sasgen I (2013) Limits in detecting acceleration of ice sheet mass loss due to climate variability. Nature Geosci., 6(8), 613-616 (doi: 10.1038/ngeo1874)

Zwally HJ, Giovinetto MB, Beckley MA and Saba JL (2012) Antarctic and Greenland drainage systems. GSF Cryospheric Sciences Laboratory, Greenbelt, MD. http://icesat4.gsfc.nasa. gov/cryo_data/ant_grn_drainage_systems.php 